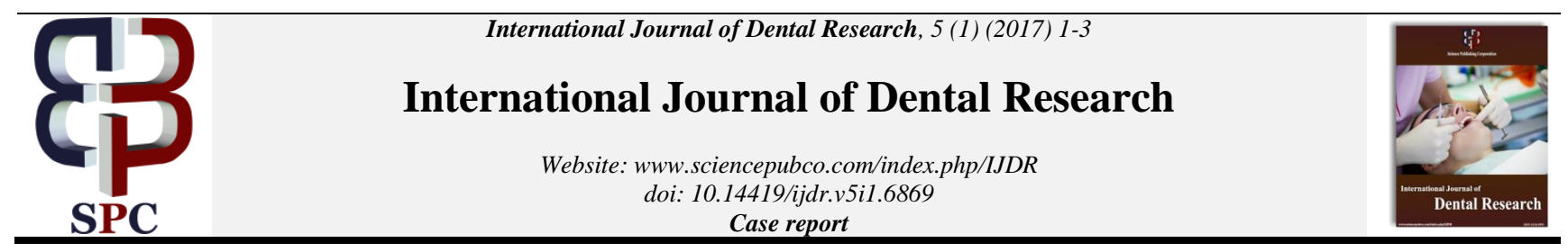

\title{
Miniplate fixation osteosynthesis of isolated mandibular symphyseal fracture without involvement of bilateral condyle in a helmet wearer
}

\author{
Karthik Shunmugavelu ${ }^{1 *}$, Kumaravel Subramaniam ${ }^{2}$ \\ ${ }^{1}$ Consultant Dental Surgeon, Department of dentistry and faciomaxillary surgery, Kasthuri Multispeciality Hospital, \\ West Tambaram, Chennai-600045, Tamilnadu, India \\ ${ }^{2}$ Consultant Oral and Maxillofacial Surgeon, Department of dentistry and faciomaxillary surgery, \\ K.P Multispeciality Hospital, Nanganallur, Chennai, Tamilnadu, India \\ *Corresponding author E-mail: drkarthiks1981@gmail.com
}

\begin{abstract}
A peculiar case of vertical mandibular symphyseal fracture in a helmet wearer has been presented. Under general anesthesia, fracture site was exposed through intraoral mandibular labial vestibule incision. Open reduction and internal fixation was done with two four holed titanium miniplates and screws. Healing was uneventful. Complete recovery was found after 6 months.
\end{abstract}

Keywords: Mandible; Titanium; Fracture; Minplate; Osteosynthesis

\section{Introduction}

Among the facial proportions, lower third is constituted by the mandible. Due to its prominent

architecture and various points of weakness, it is the most commonly fractured facial bone ( Ladeinde AL et al 2009 p.179-80, Garza JR 2002 p.769). Parts such as mentum, condyle and angle act as weaker portions when excess force is applied on them $(\mathrm{Oji}$ C 1999 p.106-109, Olson RA et al 1982 p.23-28). An isolated fracture of mandibular symphyseal region in a helmet wearer devoid of bilateral condyle is rare. Our extensive literature search proved no such case reported.

\section{Case report}

A 25 year old Indian male, a helmet wearer,reported in our department of dentistry and faciomaxillary surgery with a swollen mandibular symphyseal region due to road traffic accident.

Clinical examination revealed laceration and abrasion in face, mouth opening was limited, lateral temporomandibular joint movements satisfactory, occlusion deranged, sublingual ecchymosis and tenderness, step deformity felt during palpation (Fig 1). The general health condition was normal. Patient was conscious, oriented and afebrile. Vitals stable. No comorbidities present. Three dimensional facial computed tomography (3D facial CT) revealed an isolated vertical fracture in the mandibular symphyseal region (Fig 2, Fig 3, Fig 4). No other facial bone fractures were seen radiographically. Under general anesthesia, preparation done followed by sterile drape. The fracture site was exposed through mandibular labial vestibular incision. The fracture site was adequately reduced and two four holed miniplates and screws were used for internal fixation (Fig 5). After thorough debridement, the intra oral approach region was closed in layers. Healing was uneventful. Complete recovery was noted after 6 months. (Fig 6)

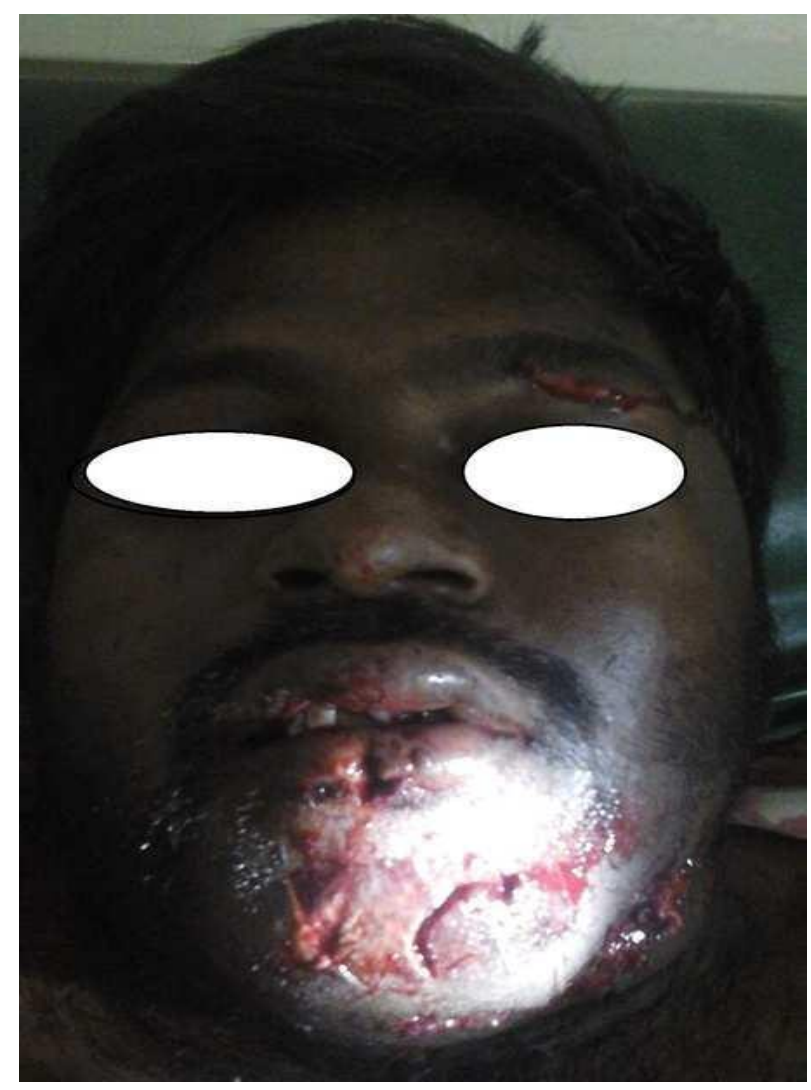

Fig 1: Preoperative clinical picture 


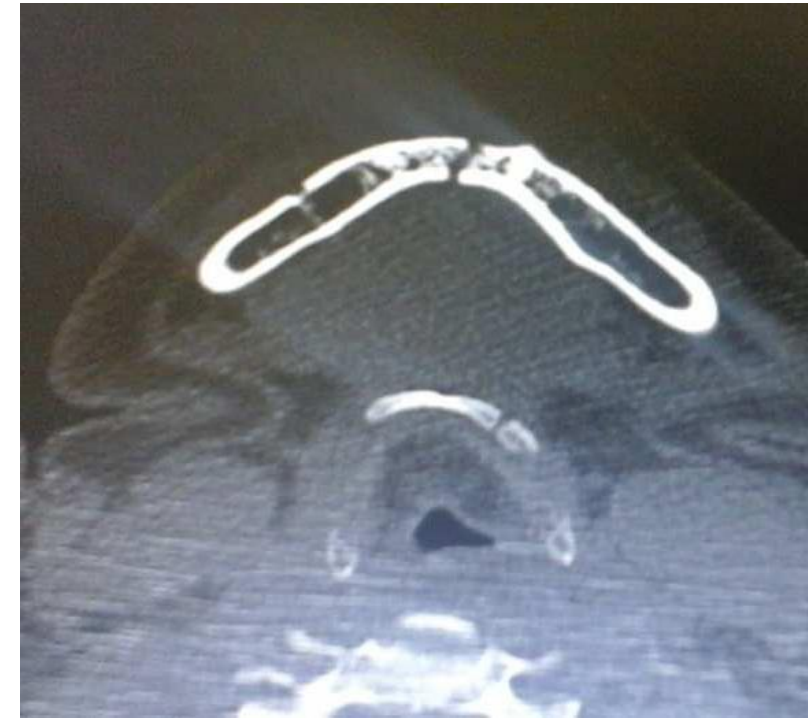

Fig 2: 3D facial $\mathrm{CT}$ axial view

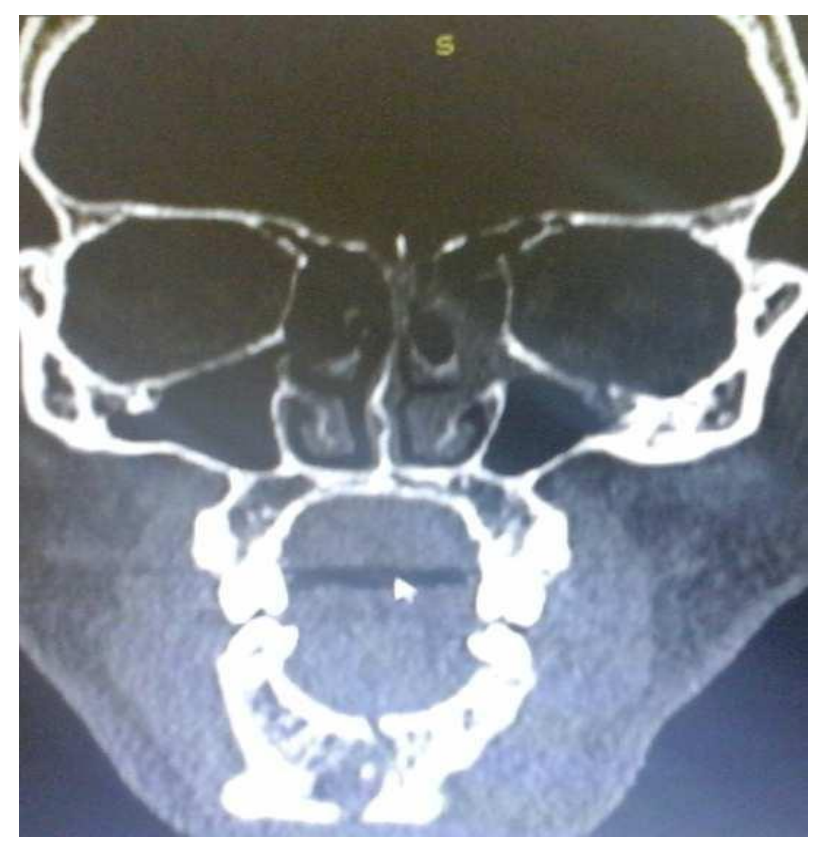

Fig 3: 3D facial CT coronal view

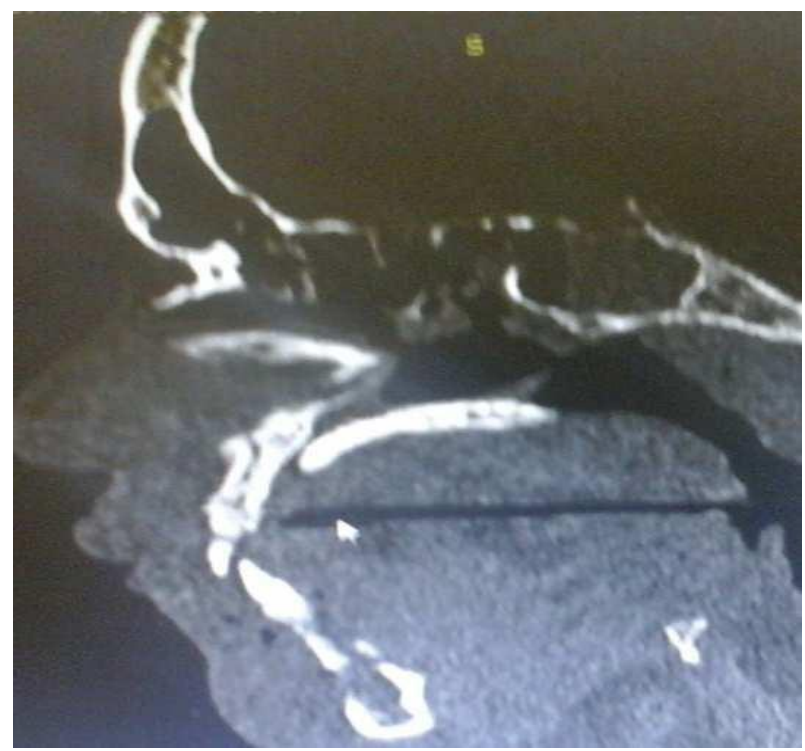

Fig 4: 3D facial CT sagittal view

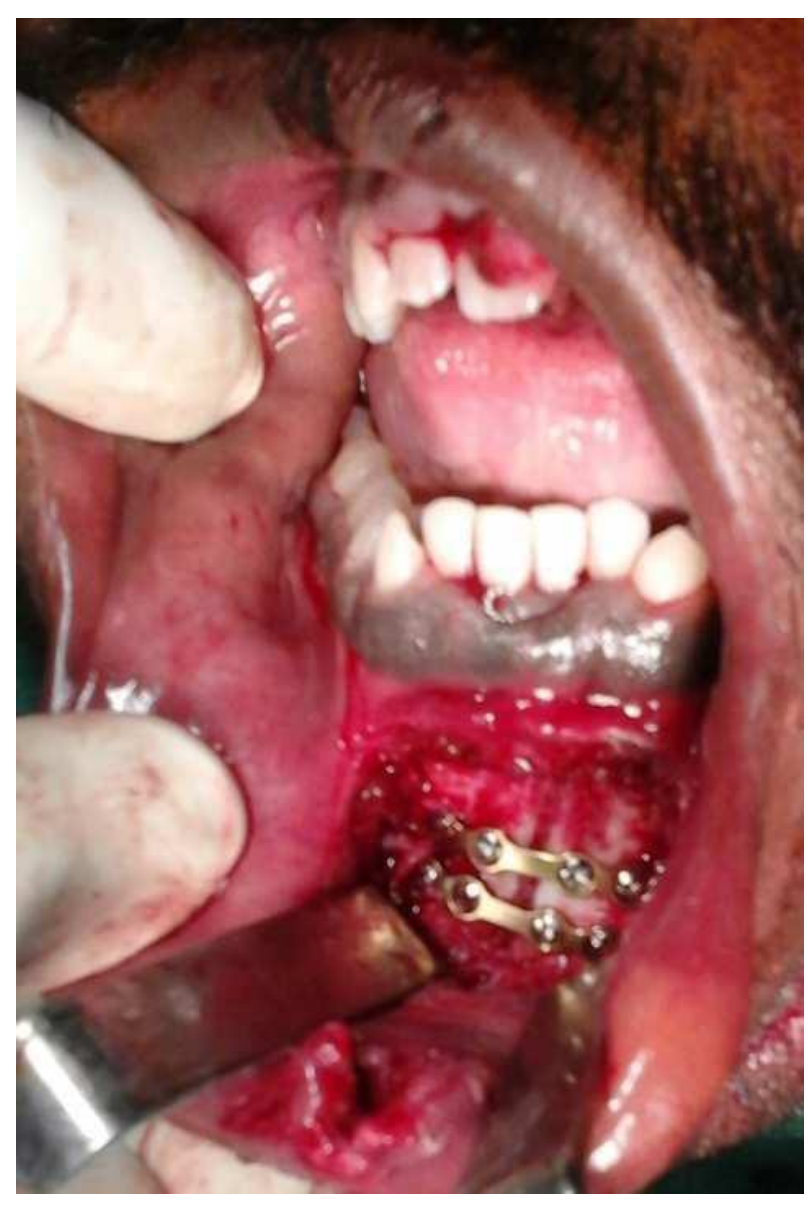

Fig 5: Intraoperative view

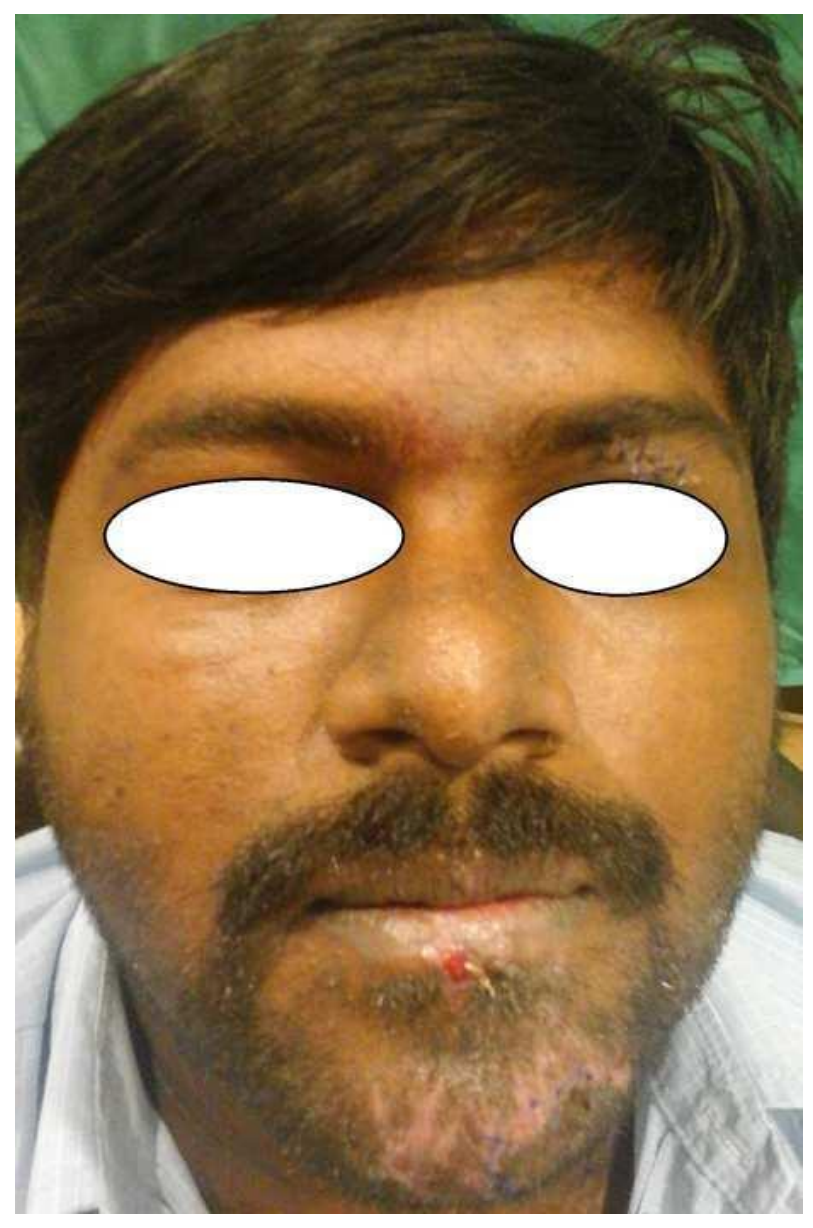

Fig 6: Postoperative clinical view 


\section{Discussion}

Mandible constitutes lower one third of the face. Most prone regions of fracture in mandible are condyle, symphysis, angle and ramus, reported due to road traffic accidents in India. Mandibular fractures have been classified based on their location, type, dentition involvement, displacement, favourability and fracture age. Based on the location, they are classified as alveolar, condylar, coronoid, ramus, angle,body, parasymphysis and symphysis (Eppley BL 2004 p.232, Banks P et al 2000 p. 1-4, 10-14,17-20, 4247, 68, 81-119.). Based on the type, they have been classified as greenstick, simple,comminuted and compound ( Hupp JR et al 2008 p. 493-495, 499-500, 502-507.). Based on tooth involvement, they have been classified as dentate ornon-dentate (Goth $\mathrm{S}$ et al 201 p.247-56). Based on the displacement, they have been classified as larger and shorter. Based on the favourability, they have been classified as favourable or unfavourable ( Pektas $\mathrm{Z}$ et al 2012 p.339-343). Based on the fracture of age, theyhave been classified as new or old (Hermund N 2008 et al p.22-26). Usual occurrence of mandibular condyle fracture in conjunctionwith symphyseal involvement results due to excess force or trauma impact. But, in our case, no condyle involvement was present. In a non-biomechanical manner, an excess force or stress at a high speed only can produce such animpact in the bone. The pathognomonic feature includes deranged occlusion, high proprioception in dentate region, mobile teeth, numbness, trismus, swelling, brusing, deformity, bleeding, open bite and sublingual ecchymosis ( Fonseca RJ et al 2012 p.10, Nair and Nair et al 2001p.689-695, Natu S et al 2012 p.1).3D facial CT plays an important role in the radiological diagnosis of mandibular fracture. The three dimension includes axial, coronal and sagittal followed by visual reformatting. Open reduction and internal fixation provide a solid stabilization of the fracture segments. Airway assessment is to be considered more in the mandibular fractures. The mobility of the central portion of the mandible to which genioglossus is attached, may lead to backward displacement of tongue resulting in airway blockage. Other airway blockades include tooth fragments of tooth itself as a whole, blood and denture. Comorbidities such as cervical spine injury and intracranial injury to be assessed along with mandibular fractures. In rare cases, severe displacement of mandible may result in damage to internal carotid and jugular vascular supply, Reduction refers to approximation of fractured segments. In case of dentate involvement, deranged occlusion can also conjointly corrected by arch bar wiring. The healing time for routine mandibular fracture is of $4-6$ weeks, irrespective of maxillomandibular fixation or rigid internal fixation. Nowdays, titanium miniplates provide stronger fixation compared to previous methods.

\section{References}

[1] Ladeinde AL, Adeyemo W, Ogunlewe M, Gbotolorun O. Ghana Med J. 2009 Dec;43(4):179-80.

[2] Garza JR. Mandibular fractures. In: Papel ID, editor. Facial plastic and reconstructive surgery. 2. New York: Thieme Medical Publishers; 2002. p. 769.

[3] Oji C. Jaw fractures in Enugu, Nigeria, 1985-1995. Br J Oral Maxillofac Surg.1999; 37:106-109 https://doi.org/10.1054/bjom.1997.0083.

[4] Olson RA, Fonseca RJ, Zeitler DL, Osbon DB. Fractures of the mandible: a review of 580 cases. J Oral MaxillofacSurg. 1982; 40:23-28 https://doi.org/10.1016/S0278-2391(82)80011-6.

[5] Eppley BL. An unusual traumatic fracture of mandibular symphysis resembling horizontal osteotomy for genioplasty (Discussion) $\mathrm{J}$ Craniofac Surg. 2004; 15:232. https://doi.org/10.1097/00001665200403000-00012.

[6] Banks P, Brown A; Brown, Andrew E. (2000).Fractures of the facial skeleton. Oxford: Wright. pp. 1-4, 10-14, 17-20, 42-47, 68, 81119.

[7] Hupp JR, Ellis E, Tucker MR (2008).Contemporary oral and maxillofacial surgery (5th ed.). St. Louis, Mo.: MosbyElsevier. pp. 493495, 499-500, 502-507.
[8] Goth, S.; Sawatari, Y.; Peleg, M. (2012). "Management of Pediatric Mandible Fractures". Journal of CraniofacialSurgery 23 (1): 47-56 https://doi.org/10.1097/SCS.0b013e318240c8ab.

[9] Pektas, Z. O.; Bayram, B.; Balcik, C.; Develi, T.; Uckan, S. (2012). "Effects of different mandibular fracturepatterns on the stability of miniplate screw fixation in angle mandibular fractures". International Journal of Oral and Maxillofacial Surgery 41 (3): 339-343 https://doi.org/10.1016/j.ijom.2011.11.008.

[10] Hermund, N. U.; Hillerup, S. R.; Kofod, T.; Schwartz, O.; Andreasen, J. O. (2008). "Effect of early or delayed treatment upon healing of mandibular fractures: A systematic literature review". Dental Traumatology 24 (1): 22-26 https://doi.org/10.1111/j.16009657.2006.00499.x.

[11] Fonseca RJ, Barber HD, Powers MP, Frost DE (2012).Oral \& maxillofacial trauma (4th ed.). W B Saunders Co.

[12] Nair, M. K.; Nair, U. P. (2001). "Imaging of mandibular trauma: ROC analysis". Academic emergency medicine: official journal of the Society for Academic Emergency Medicine 8 (7): 689-695 https://doi.org/10.1111/j.1553-2712.2001.tb00186.x.

[13] Natu, S.; Pradhan, H.; Gupta, H.; Alam, S.; Gupta, S.; Pradhan, R.; Mohammad, S.; Kohli, M.; Sinha, V. P.;Shankar, R.; Agarwal, A. (2012). "An Epidemiological Study on Pattern and Incidence of Mandibular Fractures".Plastic Surgery International 2012: 1 https://doi.org/10.1155/2012/834364. 